\title{
Evolution and long term outcome in cases with fetal diagnosis of congenital heart disease: Italian multicentre study
}

V Fesslova', S Nava, L Villa, and the Fetal Cardiology Study Group of the Italian Society of Pediatric Cardiology

\begin{abstract}
Objectives-To analyse the evolution and outcome in utero and after birth of infants with a fetal diagnosis of congenital heart disease.

Design-Inclusion criteria were the fetal diagnosis of congenital heart disease, confirmed postnatally or postmortem, and a complete follow up in utero and after birth.

Setting-20 centres operating prenatal echocardiographic screening.

Patients - 847 cases were included in the study. Gestational age at diagnosis ranged from $15-39$ weeks; in 370 cases $(43.7 \%)$ the diagnosis was made before 24 weeks' gestation.

Results-245/847 cases $(28.9 \%)$ were terminated during pregnancy, 227 following early diagnosis; $128 / 245$ cases $(52.2 \%)$ had associated anomalies and 117/245 (47.8\%) had serious congenital heart disease. Of the remaining 602 cases that continued the pregnancy, $72(11.9 \%)$ died in utero, 259 (43\%) died postnatally (83 after surgery or invasive procedures), and 271 infants $(45 \%)$ survived and presently range in age from 18 months to 13 years old. The mortality rate was higher in cases with associated extracardiac or chromosomal anomalies $(68 \%$ and $74 \%$ of cases continuing pregnancy, respectively), and in cases with heart failure and complex cardiac defects.
\end{abstract}

Conclusions-The data confirm a relevant fetal and postnatal loss in cases with complex congenital heart disease, and major clinical use of prenatal diagnosis in the management of ductus dependent anomalies. Negative prognostic factors for the outcome were associated anomalies and heart failure.

(Heart 1999;82:594-599)

Keywords: fetal echocardiography; congenital heart disease; prenatal diagnosis

Prenatal diagnosis of congenital heart disease has been made possible by means of fetal echocardiography and has become a routine part of prenatal assessment in specialised centres. Experience of groups working in this field has revealed many different aspects of cardiac problems that are detected in fetal life with respect to our postnatal knowledge, because of a different spectrum and characteristics of congenital defects. ${ }^{1-3}$ The value of early diagnosis of cardiac anomalies ${ }^{4-7}$ and its clinical impact on the outcome of affected cases is still under debate. ${ }^{8-17}$ Large series allow a better understanding of the natural history of congenital heart disease and of all clinical aspects of early diagnosis.

The objectives of our study were to examine a large number of cases with fetal diagnosis of congenital heart disease, analyse their characteristics, course in utero and following birth, and overall outcome, and evaluate the benefits of prenatal screening for congenital heart disease.

\section{Material and methods}

A multicentre retrospective study was undertaken by the fetal cardiology study group of the Italian Society of Pediatric Cardiology. The entry criteria for inclusion in the study were: the fetal diagnosis of congenital heart disease, confirmed postnatally or at postmortem examination, and a complete follow up in utero and following birth. Case data were collected from single centres using a specific questionnaire, and a computerised analysis of different aspects of the cases was subsequently performed.

Twenty centres operating in prenatal echocardiographic diagnosis took part in the study. Eighteen were second or third level centres studying selected populations of pregnancies at risk for congenital heart disease (for maternal factors such as a family history of congenital heart disease or arrhythmias, maternal diseases such as diabetes or connective tissue disorders, or infections during pregnancy) or for fetal risk factors, usually found at routine obstetric scan (associated extracardiac or chromosomal anomalies, abnormalities of the amniotic fluid volume, non-immune fetal hydrops, or fetal growth retardation). In two centres the cases were recruited from routine obstetric sonographic evaluation of the nonselected population.

Initially, 887 cases were included in the study and their outcome was analysed in a preliminary report. ${ }^{18}$ Subsequently, the follow up interval of the surviving cases was extended until the end of October 1997, and 847 cases were considered for final analysis of disease evolution and long term outcome. These cases were studied in the period between 1983 and October 1996. Gestational age at diagnosis varied from 15-39 weeks (mean (SD) 27.9 (3.2) weeks); in 370 cases ( $43.7 \%$ of the series) 
Table 1 Outcome in single types of cardiac anomalies

\begin{tabular}{|c|c|c|c|c|c|c|}
\hline \multirow[b]{2}{*}{ Cardiac anomaly } & \multirow[b]{2}{*}{$\begin{array}{l}\text { Total } \\
\text { cases } \\
(n)\end{array}$} & \multirow[b]{2}{*}{$\begin{array}{l}\text { Termination of } \\
\text { pregnancy } \\
\text { (n) }\end{array}$} & \multicolumn{4}{|c|}{ Cases continuing pregnancy } \\
\hline & & & $\begin{array}{l}\text { Total } \\
\text { (n) }\end{array}$ & $\begin{array}{l}\text { Intrauterine } \\
\text { death } \\
(n(\%))\end{array}$ & $\begin{array}{l}\text { Neonatal } \\
\text { death } \\
(n(\%))\end{array}$ & $\begin{array}{l}\text { Alive } \\
(n(\%))\end{array}$ \\
\hline Atrioventricular defect & 138 & 51 & 87 & $15(17.2)$ & $42(48.3)$ & $30(34.5)$ \\
\hline Univentricular heart & 46 & 10 & 36 & $2(5.5)$ & $29(80.5)$ & $5(14)$ \\
\hline Hypoplastic left ventricle & 119 & 48 & 71 & $6(8.4)$ & $54(77.5)$ & $10(14.1)$ \\
\hline Tricuspid atresia & 35 & 10 & 25 & $3(12)$ & $9(36)$ & $13(52)$ \\
\hline Ebstein/dysplasia of tricuspid valve & 16 & 3 & 13 & $5(38.5)$ & $3(23.9)$ & $5(38.5)$ \\
\hline Tetralogy of Fallot & 60 & 20 & 40 & $6(15)$ & $16(40)$ & $18(45)$ \\
\hline Pulmonary atresia + ventricular septal defect & 7 & 4 & 3 & - & $3(100)$ & - \\
\hline Pulmonary atresia + intact septum & 9 & 4 & 5 & - & $1(20.0)$ & $4(80.0)$ \\
\hline Double outlet right ventricle & 31 & 16 & 15 & $1(6.6)$ & $7(46.7)$ & $7(46.7)$ \\
\hline Transposition of great arteries & 39 & 9 & 30 & $1(3.3)$ & $11(36.7)$ & $18(60)$ \\
\hline Corrected transposition of great arteries & 18 & 3 & 15 & - & $2(13.3)$ & $13(86.7)$ \\
\hline Truncus & 14 & 4 & 10 & $2(20.0)$ & $7(70.0)$ & $1(10.0)$ \\
\hline Ventricular septal defect & 102 & 29 & 73 & $8(11)$ & $23(31.5)$ & $42(57.5)$ \\
\hline Atrial septal defect ostium secundum & 31 & 2 & 29 & $2(6.9)$ & $1(3.4)$ & $26(89.7)$ \\
\hline Aortic coarctation/aortic ipoplasia & 48 & 6 & 42 & $4(9.5)$ & $13(31)$ & $25(59.5)$ \\
\hline Aortic stenosis & 23 & 5 & 18 & $3(16.7)$ & $9(50.0)$ & $6(33.3)$ \\
\hline Pulmonary stenosis & 27 & 5 & 22 & $1(4.5)$ & $7(31.8)$ & $14(63.6)$ \\
\hline Dilated cardiomyopathy & 14 & 3 & 11 & $1(9.1)$ & $8(72.7)$ & $2(18.2)$ \\
\hline Myocarditis & 10 & 1 & 9 & $4(44.5)$ & $3(33.3)$ & $2(22.2)$ \\
\hline Hypertrophic cardiomyopathy & 33 & 8 & 25 & $6(24)$ & $7(28)$ & $12(48)$ \\
\hline Tumours & 16 & 1 & 15 & $1(6.7)$ & $1(6.7)$ & $13(86.6)$ \\
\hline Others & 11 & 3 & 8 & $1(12.5)$ & $3(37.5)$ & $5(62.5)$ \\
\hline Total series & 847 & 245 & 602 & $72(12)$ & 259 (43) & $271(45)$ \\
\hline
\end{tabular}

the diagnosis was made before 24 weeks. Median postnatal follow up was three years (range 1-13 years). Analysis of this series was undertaken with respect to the presence of other associated factors and to the type of congenital heart disease.

\section{Results}

GENERAL ASPECTS OF THE STUDY

Of the 20 centres participating, four began performing prenatal cardiac diagnosis in the mid-1980s, while the remaining centres started later; 239 cases were diagnosed before 1991 and the other 608 cases after.

DIAGNOSTIC PRECISION

Incomplete or incorrect diagnosis was made in 114 cases $(13.4 \%)$, involving complex congenital heart disease or isomerisms.

CHARACTERISTICS OF THE SERIES

Table 1 summarises the frequency of single cardiac anomalies, with their relative outcomes. Prevalence of congenital heart disease

Table 2 Frequency of extracardiac and chromosomal anomalies, and heart failure in single types of congenital heart disease

\begin{tabular}{lccc}
\hline Type of congenital heart disease & $\begin{array}{l}\text { Extracardiac } \\
\text { anomalies } \\
(\%)\end{array}$ & $\begin{array}{l}\text { Chromosomal } \\
\text { anomalies } \\
(\%)\end{array}$ & $\begin{array}{c}\text { Heart } \\
\text { failure } \\
(\%)\end{array}$ \\
\hline Atrioventricular defect & 13.8 & 47.1 & 8.0 \\
Univentricular defect & 17.8 & 6.7 & 4.3 \\
Hypoplastic left heart syndrome & 10.9 & 4.2 & 8.4 \\
Tricuspid atresia & 34.3 & 8.6 & 5.7 \\
Tetralogy of Fallot & 25.0 & 26.7 & 1.7 \\
Double outlet right ventricle & 19.3 & 45.2 & 3.2 \\
Truncus & 21.4 & 28.6 & 14.3 \\
Transposition of great arteries & 25.6 & 2.6 & 2.6 \\
Corrected transposition of great arteries & 5.6 & 0 & 0 \\
Ebstein/dysplasia of tricuspid valve & 6.25 & 6.25 & 31.25 \\
Ventricular septal defect & 37.1 & 37.2 & 3.9 \\
Atrial septal defect ostium secundum & 16.1 & 3.2 & 3.2 \\
Aortic coarctation & 12.5 & 20.8 & 8.3 \\
Aortic stenosis & 13 & 17.4 & 13.0 \\
Pulmonary stenosis & 25.9 & 3.7 & 11.1 \\
Dilated cardiomyopathy & 28.6 & 0 & 57.1 \\
Myocarditis & 0 & 0 & 30.0 \\
Hypertrophic cardiomyopathy & 57.6 & 0 & 12.5 \\
Tumours & 6.25 & 12.5 & \\
\hline
\end{tabular}

was higher in cases referred to prenatal echocardiographic evaluation for fetal risk. A total of 468 cases $(55.2 \%)$ were sent because of suspected cardiac findings at routine obstetric ultrasound; $162(19.1 \%)$ and $166(19.6 \%)$ fetuses had associated extracardiac or chromosomal anomalies, while isolated congenital heart disease was present in the remaining 519 cases $(61.3 \%)$.

Table 2 shows the frequency of extracardiac and chromosomal anomalies, and heart failure in various types of congenital heart disease. A higher frequency of chromosomal anomalies was present in cases with atrioventricular defect and double outlet right ventricle, while extracardiac anomalies were found more frequently in fetuses with ventricular septal defect, tricuspid atresia, conotruncal anomalies, and in cases with dilated and hypertrophic cardiomyopathy. Cardiac hypertrophy was found in $19 / 33$ cases $(57.6 \%)$, in the presence of renal or other organ malformations, and in seven infants of mothers with gestational or pregestational diabetes.

Table 3 illustrates the types of cardiac defects present in major chromosomal anomalies, and table 4 indicates the frequency of extracardiac anomalies according to the type of disorder. Thirty fetuses had multiple extracardiac anomalies.

Seventy three cases $(8.6 \%)$ showed signs of heart failure (hydrops fetalis) at diagnosis in utero or subsequently during the fetal follow up; 13 cases were mild (with fluid collection in one serous cavity only), while the remaining cases were moderate to severe (presence of fluid collection in two or three cavities and subcutaneous oedema). This complication occurred more frequently in fetuses with myocardial disease (dilated cardiomyopathy or myocarditis), as indicated in table 2 .

Recurrence of congenital heart disease occurred in 57 cases ( $6.7 \%$ of the series). Forty one fetuses were found to have associated arrhythmias: extrasystolic arrhythmias in 15 
Table 3 Types of congenital heart disease in major chromosomal anomalies

\begin{tabular}{|c|c|c|}
\hline Chromosomal anomaly & $\begin{array}{l}\text { Total } \\
\text { cases } \\
(n)\end{array}$ & Type of congential heart disease (number of cases) \\
\hline Trisomy 21 & 59 & $\begin{array}{l}\text { Atrioventricular defect (41), ventricular septal defect (7), } \\
\text { tetraology of Fallot (4), double outlet right ventricle (3), } \\
\text { transposition of great arteries (1), dysplasia of tricuspid } \\
\text { valve (1), mitral anomaly (1), tumour (1) }\end{array}$ \\
\hline Trisomy 18 & 62 & $\begin{array}{l}\text { Ventricular septal defect (27), atrioventricular defect (13), } \\
\text { double outlet right ventricle (8), univentricular heart (3), } \\
\text { truncus (3), ventricular septal defect + pulmonary stenosis } \\
\text { (3), tetralogy of Fallot (1), transposition of great arteries } \\
\text { (2), hypoplastic left ventricle (2) }\end{array}$ \\
\hline Trisomy 13 & 18 & $\begin{array}{l}\text { Truncus (4), double outlet right ventricle (4), pulmonary } \\
\text { atresia + ventricular septal defect (3), tetralogy of Fallot } \\
\text { (2), atrioventricular defect (2), univentricular heart (1), } \\
\text { hypoplastic left ventricle (1), ventricular septal defect (1) }\end{array}$ \\
\hline Turner syndrome & 6 & $\begin{array}{l}\text { Hypoplastic left ventricle (1), tetralogy of Fallot (1), aortic } \\
\text { coarctation (3), aortic stenosis (1) }\end{array}$ \\
\hline Trisomy 22 & 1 & Tricuspid atresia + pulmonary atresia \\
\hline Triploidy & 2 & Ventricular septal defect (2) \\
\hline Klinefelter syndrome & 1 & Aortic coarctation \\
\hline
\end{tabular}

Table 4 Types of extracardiac anomalies in 162 fetuses

\begin{tabular}{ll}
\hline Extracardiac anomaly & $\begin{array}{l}\text { Total number of cases } \\
(\%)\end{array}$ \\
\hline Central nervous system & $38(23.4)$ \\
Urogenital system & $51(31.5)$ \\
Gastrointestinal system & $16(9.9)$ \\
Abdominal wall & $23(14.2)$ \\
Labiopalatoschisis & $7(4.3)$ \\
Extremities & $7(4.3)$ \\
Others & $5(3.1)$ \\
\hline
\end{tabular}

The major extracardiac anomaly is considered in this subdivision (multiple anomalies occurred in 30 fetuses).

cases; supraventricular tachyarrhythmias in four cases (dilated cardiomyopathy, pulmonary atresia, aortic coarctation, and atrioventricular defect); and total atrioventricular block in 22 cases (13 cases with isolated or complex atrioventricular defect, three with univentricular heart, one with tricuspid atresia, three with corrected transposition of the great arteries, one with ventricular septal defect, and one with pulmonary stenosis).

\section{OUTCOME}

The mothers of $245 / 847$ cases $(28.9 \%$ of the series) opted for pregnancy termination, 227 of those with an early diagnosis; $128 / 245$ cases $(52.2 \%)$ had associated extracardiac or chromosomal anomalies, while 117/245 (47.8\%) had serious congenital heart disease.

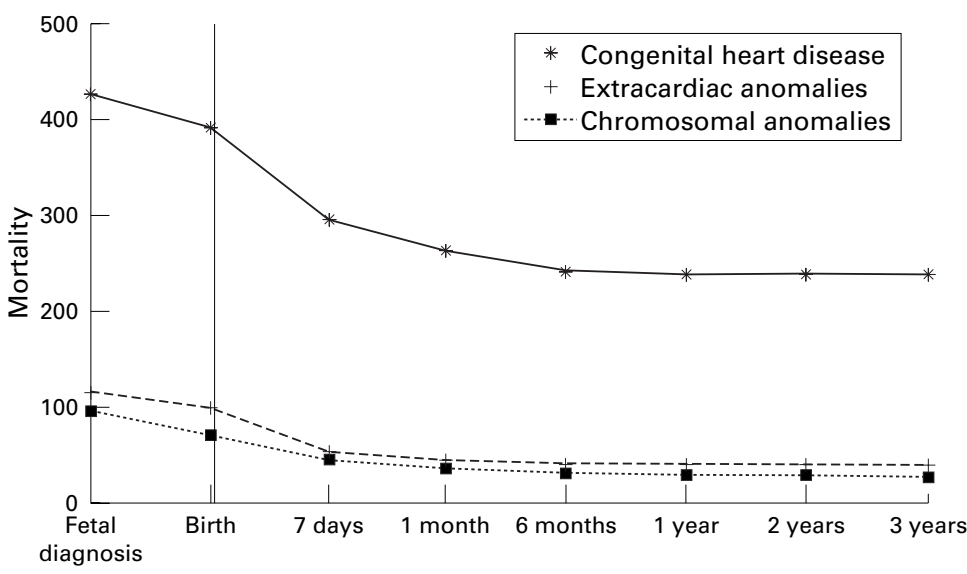

Figure 1 Mortality in cases with isolated congenital heart disease, and associated extracardiac and chromosomal anomalies.
Of the remaining 602 cases that continued the pregnancy, $72(11.9 \%)$ died in utero, 259 (43\%) died postnatally, and 271 infants $(45 \%)$ survived and presently range in age from 18 months to 13 years old. Table 1 provides further details on the percentage of infants not terminated that died or survived, according to the type of cardiac defect.

A planned delivery was usually organised in specialised centres, in order to optimise the postnatal management in cases with ductus dependent cardiac defects.

Invasive procedures (Rashkind septostomy, valvuloplasty of the pulmonary or aortic valve) were performed after birth in 35 cases; five died and 20 subsequently underwent cardiac surgery.

A total of 205 infants underwent the first step of cardiac surgery, 42 of them subsequently underwent the second step, and seven the third step; 78 infants (38\%) died after surgery (a total of 83 infants died after surgery or invasive procedures). Of 31 cases with hypoplastic left heart syndrome in which the Norwood procedure was performed, 22 died after the first step, seven infants underwent the second step operation, and four underwent the third step, with all surviving. One infant with hypertrophic cardiomyopathy underwent cardiac transplantation at the age of 1 year and survived.

The overall mortality was higher in cases with associated extracardiac or chromosomal anomalies-76/112 (67.8\%) and 67/91 (74\%), respectively, of cases that continued pregnancy. Figure 1 shows the mortality curve in cases with isolated congenital heart disease and with associated extracardiac and chromosomal anomalies; all three groups had highest mortality rates in utero and within the first month of life.

The mortality rate was higher in fetuses with myocardial disease, anomalous or absent atrioventricular connections, and atrioventricular defect $(64 \%, 77 \%$, and $65.5 \%$, respectively) and in those cases complicated by heart failure. Of 73 cases, seven pregnancies were terminated, 20 died in utero, and 36 died postnatally; only $10 / 67$ infants $(14.9 \%)$ that were not terminated survived.

Mortality rate was high in those cases with isomerism. Of 21 cases (13 with left isomerism and eight with right isomerism, in one case associated to trisomy 18), only four infants (19\%) remain alive (aged between 5 months and 6 years).

Mortality was also high in the presence of total atrioventricular block. Of 22 cases, seven pregnancies were terminated, while 12 of the remaining 15 cases $(80 \%)$ died (five in utero and seven following birth). A postnatal pacemaker implant was performed in five infants but only three survived.

Survival was higher in cases of isolated congenital heart disease (212/402 cases $(52.7 \%)$ that continued pregnancy) and in less complex lesions (table 1). 
EVOLVING ASPECTS OF LESIONS IN UTERO Complications caused by heart failure

Cardiac anomalies such as myocardial disease, atrioventricular defect, Ebstein or non-Ebstein anomaly of the tricuspid valve, and truncus arteriosus were frequently complicated by heart failure, at diagnosis in utero or later on, during the course of pregnancy. Rarely, some simple anomalies, such as ventricular septal defect or aortic coarctation, presented signs of fetal hydrops, likely to be in consequence of other fetal-placental factors.

\section{Evolution of the anatomic-haemodynamic situation}

Cardiac features modified in some cases during fetal life. Three fetuses showed a progression from characteristics of pulmonary stenosis to pulmonary atresia (in two of them in presence of non-Ebstein dysplastic tricuspid valve), two other cases developed more distinct left ventricular hypoplasia in atrioventricular defect with right ventricular dominance, and one fetus showed progression from the features of left ventricular endocardial fibroelastosis towards a hypoplastic left heart syndrome. There were also two fetuses that presented in utero with a malaligned subaortic defect and normal sized pulmonary artery which evolved after birth into a moderate form of tetralogy of Fallot.

\section{Discussion}

The composition of our series corresponds to other reports, all of which have indicated a higher prevalence of more complicated heart defects and a higher frequency of association of extracardiac and chromosomal anomalies detected prenatally than in infants with congenital heart disease diagnosed in the first year of life. ${ }^{1-461719}$ This is partly artificial, reflecting the fact that cases were frequently referred for fetal echocardiography for the finding of associated extracardiac problems at the first level of obstetric ultrasonography, or for the finding of an abnormal four chamber view, that usually corresponds to more severe cardiac anomalies. As has been previously stated, part of the difference between the prenatal and postnatal spectrum of congenital heart disease is certainly the result of a high prenatal loss in cases with complex cardiac disease or in those with multiple malformations. Chromosomal anomalies occurred in our fetal series quite frequently and also in some cardiac defects in which their finding postnatally is considered to be rare (in tetralogy of Fallot, hypoplastic left heart syndrome, and also in one case with right isomerism).

In contrast to some other fetal studies, more than half of the cases in this study were diagnosed during the late second or third trimester. This explains the relatively high frequency of minor cardiac anomalies, such as ventricular septal defects, that may not be detected during early pregnancy. This study also included cases in which the presence of ostium secundum atrial septal defect was diagnosed or suspected at the third trimester echocardiography. The diagnosis was usually based on the features of an abnormal prevalence of the right ventricle with respect to the normal standard values for the gestational age, with a wide open foramen ovale exceeding $8 \mathrm{~mm}$ as a standard for the third trimester. ${ }^{20}$ Only those cases with a postnatal presence of a haemodynamically significant atrial septal defect, over 6 months of age, were included in this study. There was also a relatively high frequency of cases with features of hypertrophic cardiomyopathy of a secondary form, associated with maternal diabetes or extracardiac anomalies, often renal. Otherwise, $2 / 7$ infants with idiopathic form had specific recurrence of familial hypertrophic cardiomyopathy, and this anomaly occurred in another one with a family history of tetralogy of Fallot in a previous child.

The entry criteria for our study, and the exclusion of those cases with a prenatal diagnosis of congenital heart disease but lost at follow up, may represent a bias in our study, both for the composition of the series and for the data related to the outcome of pregnancy (option for termination or continuation of pregnancy).

The overall frequency of termination of pregnancy was lower in our series than in some other reports..$^{2-5} 17$ However, if we consider the cases with early diagnosis, $60 \%$ of mothers chose this option, $58 \%$ of them because of multiple malformations and the remainder because of the heart problem alone.

Data from our multicentre study confirm a relevant fetal and postnatal loss in cases with complex congenital heart disease, in which early diagnosis does not usually increase the chances of survival. Negative prognostic factors for the outcome were the presence of other associated anomalies, heart failure, and more complex cardiac anomalies, in agreement with previous reports. ${ }^{56}$

Analysis of the course of various cardiac lesions confirms a more frequent complication already in utero by heart failure in defects with anatomic predisposition for valvar insufficiency (such as in Ebstein or non-Ebstein anomaly of the tricuspid valve, atrioventricular defect, and truncus arteriosus, because of the dysplastic truncal valve), or in anomalies with impaired myocardial contractility and reduced cardiac output (dilated cardiomyopathy/endocardial fibroelastosis, myocarditis or severe aortic stenosis, in which huge mitral insufficiency occurs together with the left ventricular contractile impairment). ${ }^{21-24}$ Reduced cardiac output is also a cause of heart failure in fetuses with total atrioventricular block. ${ }^{25}$ There were, however, some cases in our series in which heart failure occurred in simple cardiac defects without a real haemodynamic reason for cardiac failure (isolated ventricular septal defect or aortic coarctation); in these cases we may suppose the cause to be an infection or a combination of multiple fetal-placental factors.

It was possible to observe in some cases modifications of cardiac morphology and function during the fetal follow up. Prenatal worsening of the pulmonary obstruction has already been documented ${ }^{26}$; in our series it occurred in two fetuses with associated tricuspid valve 
dysplasia, poorly functioning right ventricle, and a greatly reduced flow to the pulmonary artery at initial observation. Changing features of left ventricular disease from endocardial fibroelastosis to hypoplastic left heart syndrome, and worsening of the degree of left ventricular hypoplasia in atrioventricular defect with right ventricular dominance, confirm the variability of different forms of left ventricular disease that are considered to be one pathological entity. ${ }^{27-31}$

The evolution of a malaligned subaortic ventricular septal defect towards a form of tetralogy of Fallot after birth is also known to occur from the postnatal experience; this progression is less common in fetal life, but has to be kept in mind during early prenatal screening.

From our joint experience we can confirm that in specialised hands an accurate diagnosis of complex heart defects is possible, as has been reported by other groups working with fetal echocardiography. ${ }^{2} 8121417$ An incomplete diagnosis of minor associated cardiac anomalies does not usually influence the management and outcome of affected cases (with the exception of total anomalous pulmonary venous return). This study was not aimed at evaluating the diagnostic precision of prenatal diagnosis and false negative cases were not included in the analysis. Screening for cardiac anomalies in the third trimester showed problems in evaluating cases with a major degree of prevalence of the right ventricle; it is known that some of these cases are found postnatally without any real haemodynamically important cardiac anomaly, while others may present mild aortic coarctation or a future atrial septal defect. ${ }^{32}$

Ductus dependent anomalies did not generally present major problems in utero in our series, apart from some rare cases with retarded fetal growth. This category of patients should find major benefit from prenatal diagnosis, considering the opportunity of a planned birth in qualified centres and the reduction of diagnostic delay after birth. ${ }^{33-35}$ Despite this consideration, surgical mortality was quite high in our series. However, it is difficult to make a correct comparison with the surgical results in those cases with postnatal diagnosis of similar anomalies. This is because of the limited number of cases for single anomalies in this study, treated in different centres, and the lack of comparative studies of this kind, if we exclude two reports regarding hypoplastic left heart syndrome. ${ }^{33} 34$ This anomaly had a very poor outcome in our series, when the Norwood procedure was attempted, as well as in some other reports ${ }^{36}$; however, we have to consider the small number of cases in single centres and the fact that these data reflect, in the majority of cases, an initial surgical experience with this difficult operation.

Screening for congenital heart disease in cases with a family history might not seem productive if we consider the relatively low prevalence of heart defects detected. However, the results of this and another study show a higher recurrence rate of congenital heart disease than reported previously, with a high specific recur- rence of serious anomalies such as hypoplastic left heart, atrioventricular defect, tetralogy of Fallot, or hypertrophic cardiomyopathy. ${ }^{37} 38$

Our data do not show a true benefit from fetal diagnosis in regards to outcome and cannot contrast the voices of pessimism regarding the clinical use of the screening. ${ }^{39}$ However, it is our opinion that as general ultrasonic evaluation is a routine part of pregnancy management nowadays, the possibility of an early diagnosis of a cardiac anomaly should be offered to parent(s), and the detection of cardiac problems at the basic obstetric screening level should increase. Improvement in the outcome of affected cases will also depend on the improvement of surgical skills and perioperative management.

\section{Appendix}

Members of the Fetal Cardiology Study Group of the Italian Society of Pediatric Cardiology: L Acanfora, G Agnoletti, M Bellotti, A Benettoni, G Bricchi, E Chiappa, A Cipriani, V Colloridi, C Comparato, C Condoluci, R Crepaz, F De Luca, L De Simone, G Errico, S Gerboni, C Groli, S Mandorla, O Milanesi, W Moroder, A Pachì, G Pacileo, D Paladini, M Papa, GL Pilù, S Pipitone, A Pizzutti, D Prandsträller, G Rossi, MA Rustico, S Secchieri, D Spagnolo, F Taddei, $M$ Tibaldi, T Todros.

1 Allan LD, Crawford DC, Anderson RH. Spectrum of congenital heart disease detected echocardiographically in prenatal life. Br Heart 7 1985;54:523-6.

2 Allan LD, Crawford DC, Chita SK, et al. Prenatal screening for congenital heart disease. BMF 1986;29:1717-19.

3 Fermont L, Batisse A, Le Bidois J. Cardiologie prenatale: peut-on traiter le coeur du foetus? Pediatrie 1992;47: peut-on

4 Sharland GK, Allan LD. Screening for congenital heart disease prenatally: results of a two and a half year study in the south east Thames region. Br f Obstet Gynaecol 1992;99: $220-5$.

5 Sharland GK, Lockhart SM, Chita SK, et al. Factors influencing the outcome of congenital heart disease detected prenatally. Arch Dis Child 1990;65:284-7.

6 Fesslova' V, Bellotti M, Pirozi I, et al. Evolution and survival of 244 cases with prenatal diagnosis of congenital heart disease. Developmental Physiopathology and Clinics 1993;4: $11-23$.

7 Smythe JF, Copel JA, Kleinman CS. Outcome of prenatally detected cardiac malformations. Am f Cardiol 1992;69: 1471-4.

8 Bromley B, Estroff JA, Sanders SP, et al. Fetal echocardiography: accuracy and limitations in a population at high and low risk for heart defects. Am f Obstet Gynecol 1992;166:1473-81.

9 Martin GR, Ruckmann RN. Fetal echocardiography: a large clinical experience and follow-up. $\mathcal{F} \mathrm{Am}$ Soc Echocardiogr 1991;3:4-8

10 Rustico MA, Benettoni A, D'Ottavio G, et al. Fetal heart screening in low-risk pregnancies. Ultrasound Obstet Gynecol 1995;6:313-19.

11 Kirk JS, Comstock CH, Lee W, et al. A five year experience with 111 abnormal fetal hearts: detected versus undetected [abstract]. Am f Obstet Gynecol 1996;174:419.

12 Buskens E, Stewart PA, Hess J, et al. Efficacy of fetal echocardiography and yield by risk category. Obstet Gynecol 1996;87:423-8.

13 Sahn DJ. Perspectives in fetal echocardiography. Cardiology in the Young 1994;4:90-8.

14 Wyllie J, Wren C, Hunter S. Screening for fetal cardiac malformations [abstract]. Br Heart f 1994;71 (suppl):20-5.

15 Todros T, Faggiano F, Chiappa E, et al. Accuracy of routine ultrasonography in screening heart disease prenatally. Gruppo Piemontese for prenatal screening of congenital heart disease. Prenatal Diagnosis 1997;17:901-6.

16 Stark J. Predicting the unpredictable. Eur $\mathcal{f}$ Cardiothorac Surg 1994;8:1-6.

7 Skovranek J, Marek J, Povysilova V. Prenatalni kardiologie. Cesk Pediat 1997;52:332-8.

18 Fesslova V, and the Fetal Cardiology Study Group of the Italian Society of Pediatric Cardiology: Outcome in 887 cases with fetal diagnosis of congenital heart disease: multicenter study. In: Imai Y, Momma K, eds. Proceedings of the Second World Congress of Pediatric Cardiology and Cardiac Surgery. Armonk, New York: Futura, 1998:106-7.

19 Greenwood RD, Rosenthal A, Parisi L, et al. Extracardiac abnormalities in infants with congenital heart disease. Pediatrics $1975 ; 55: 485-92$.

20 Fesslova' V. Manuale Atlante di ecocardiografia fetale. Milano: Ghedini, 1996: 35-44. 
21 Kleinman CS, Donnerstein RL, De Vore GR, et al. Fetal echocardiography for evaluation of in utero congestive echocardiography for evaluation of in utero

22 Silverman NH, Kleinman CS, Rudolph AM, et al. Fetal atrioventricular valve insufficiency associated with nonimmune hydrops: a two-dimensional echocardiographic and pulsed Doppler ultrasound study. Circulation 1985;72:825-32.

23 Fesslova V, Bellotti M, Pirozzi I, et al. Myocardial disease diagnosed in utero: features and outcome in 24 cases. Four nal of Maternal and Fetal Investigation 1993;3:249-54.

24 Hornberger LK, Sahn DJ, Kleinman CS, et al. Tricuspid valve disease with significant tricuspid insufficiency in the
fetus: diagnosis and outcome. $\mathcal{F}$ Am Coll Cardiol 1991;17: 167-73.

25 Schmidt KG, Ulmer HE, Silvermann NH, et al. Perinatal outcome of complete atrioventricular block: a multicenter experience. F Am Coll Cardiol 1991;17:1360-6.

26 Todros T, Presbitero P, Gagliotti P, et al. Pulmonary stenosis with intact ventricular septum, documentation of development of the lesion echocardiographically during fetal life. Int $\mathcal{F}$ Cardiol 1988;19:356-60.

27 Allan LD, Sharland G, Tynan MG. The natural history of the hypoplastic left heart syndrome. Int $\mathcal{F}$ Cardiol 1989;25: 343-6.

28 Allan LD, Cook A, Sullivan L, et al. Hypoplastic left heart syndrome: effects of fetal echocardiography on birth prevalence. Lancet 1991;337:959-61.

29 Sharland GK, Chita SK, Fagg NLK, et al. Left ventricular dysfunction in the fetus: relation to aortic valve anomalies and endocardial fibroelastosis. Br Heart $\mathcal{F}$ 1991;66:419-24

30 Fesslova' V, Villa L, Nava S. Evolution of the left ventricular disease in the fetus: a case report. Fetal Diagn Ther 1999;14:60-2.
31 Yates RWM, Sharland GK, Quareshi SA. The evolution of hypoplastic left ventricle in an infant with atrioventricular septal defect detected antenatally. Cardiology in the Young 1995;5:360-2

32 Sharland GK, Chan KY, Allan LD. Coarctation of the aorta: difficulties in prenatal diagnosis. Br Heart $\mathcal{F} 1994 ; 71: 70-5$.

33 Chang AC, Huhta JC, Yoon GY, et al. Diagnosis, transport and outcome in fetuses with left ventricular outflow tract obstruction. F Thorac Cardiovasc Surg 1991;102:841-8.

34 Tworetzky W, McElhinney DB, Tometzki A, et al. Improved surgical outcome after fetal diagnosis of hypoplastic left heart syndrome [abstract]. Cardiology in the Young 1998; 9(suppl 1):3.

35 Chantepie A, Cloarec S, Blaysat G, et al. Preoperative mortality in transposition of the great arteries [abstract]. Cardiology in the Young 1998;9(suppl 1):28.

36 Dhillon R, Redington A. Outcome of surgical approaches to the hypoplastic left heart syndrome. Cardiology in the Young 1997;7:242-4.

37 Allan LD, Crawford DC, Chita SK, et al. Familial recurrence of congenital heart disease in a prospective series of mothers referred for fetal echocardiography. Am $\mathcal{F}$ Cardiol 1986;58:334-3.

38 Fesslova' V, Nava S, Villa L. Recurrence of congenital heart disease in fetuses with familial risk screened prenatally by echocardiography [abstract]. Cardiology in the Young 1998; 9(suppl 1):13.

39 Montana E, Khoury MJ, Cragan JD, et al. Trends and outcome after prenatal diagnosis of congenital cardiac malformations by fetal echocardiography in well defined birth population, Atlanta, Georgia, 1990-1994. I Am Coll Cardiol 1996;2:1805-9. 